\title{
Moral potential and eco-responsibility in the modern socio-economic conditions of Russia
}

\author{
Dina Kazantseva ${ }^{1, *}$, Sergey Tarasov $^{2}$, Irina Medvedeva ${ }^{2}$,Elena Tarasova ${ }^{2}$, and Ekaterina \\ Baranova $^{3}$ \\ ${ }^{1}$ Yuzhny Federal University, 344006, Bolshaya Sadovaya st., 105/42, Rostov-on-Don, Russia \\ ${ }^{2}$ Penza State University, 440026, st. Lermontov, 37, Penza, Russia \\ ${ }^{3}$ Russian State Agrarian University-Moscow Agricultural Academy named after K.A.Timiryazev, \\ 127550, Timiryazevskaya st., 49, Moscow, Russia
}

\begin{abstract}
In times of crisis, stabilization of the sphere of socio-economic activity implies appearance of moral potential as the framework for the mental matrix and standard, traditional economic behavior pattern of the Russians. The purpose of the article is to reveal the features of moral potential manifestation of a person in the sphere of socio-economic activities in modern Russia. Theoretical and methodological basis of scientific studies is interdisciplinary approach, neo-classical approach, and multifactorial approach. Transdisciplinary approach unites those approaches with common objective and functions as an integrative program of the study. Effectiveness of economic activity and future economic results depend on the extent of development of economic activity patterns that are hidden in mental molds and traditional mental matrices of the people and determined by the system of values and ideas, attitudes and especially their moral potential. One can survive in a world of global civilizational crises only under condition of realization of their moral potential as the basic foundation of the people's economic mentality feature, since its development laws regulate both industrial and social relations and determine the future of a particular country as well as of all mankind.
\end{abstract}

\section{Introduction}

Manifestation of moral potential in the field of socio- economic activity determines synchronization of the usage of materials and human resources. Economic sphere rationality in material resources using is balanced by human potential, deep intrinsic needs and behavioral patterns. In modern world, where potential human resources are realized to a limited extent and therefore material resources for any problem solving are produced to a limited extent, optimization of human and material components interaction requires the potential to be updated and implemented.

Deteriorating economic model due to abandoning inner moral cultural standards has led modern world to civilizational crisis, triggered uncontrollable trends in technosphere evolution, interfered with in-depth nature of man, degraded human needs from

\footnotetext{
${ }^{*}$ Corresponding author: petrovaelena2010@yandex.ru
} 
superior spiritual to inferior physiological ones, transformed methods of new technologies application in regulation of economic activity, caused numerous distortions of essential matters. New needs, values and motives are being rapidly developed; new man is being created with accentuation on human brain, as their main function; with essential basic human traits and even body parts being gradually liquidated. New public sphere is being maintained where a person is used as biological material, a resource with minimal development of their human qualities. People are no longer representing selffulfilling potential, but turning into resource of the body.

The underlying cause of this process is a shift in the structure of social consciousness that affects production. Loss of moral imperatives has launched the economic crisis mechanism that, in turn, breaks production chains, transforms the very nature of production process, system of social relations, person's needs and values, the basic foundations of their conventional world. Visible trends present versatile necessity of deformation leap that is already in progress, the quality of which needs serious consideration.

With a large number of mock-reasonable trends distorting the essence of man and society development and objective reality of the on-going situation, only methodological scope of scientific research can allow it to notice reasons and essence of social shifts, economic institutions' functioning peculiarities, cause-and-effect relationships of moral and natural human reality distortion and the lack of implementation capacity.

A person is historically a bearer of mental programs and mental matrices of behavior, within the framework of which the self-realization of their potential takes place. Thanks to those programs people in different social environment construct entity basic foundations of their program within various repertoires of social actions and behavior. Within the scope of Russian mentality, this process is accompanied by comprehension of superior moral intrinsic values and meanings, and by realization of moral potential. Mental matrix and normative (traditional basic) model of the economic behavior of Russians are stable, unconscious and not reflexive by nature. The dominant values of Russians lead to comprehension of the meaning of life and self-realization.

All the foregoing shows the need of consideration of economic spheres within the framework of mental program, people's household tradition and their economic mentality, determining economic behavior of an individual and character of the society, as well as the mental matrix of existence, values and moral meanings, manifestations of moral potential features in specific conditions of historical development.

\section{Materials and methods}

The study of moral potential in the field of social and economic activity should be considered in terms of data obtained from economics, philosophy, psychology, sociology, political science, cultural studies, and many others. In this regard, an interdisciplinary approach that allows solving problems at the junction of various scientific disciplines with their own methodological means and conceptual theories is fundamental. In this way paradigmatic limitations and disciplinary one-sidedness of research practices are overcome.

The use of neo-classical approach allows tracing neatly the connection of values, beliefs, experiences, traditions and living conditions that model economic behavior and mentality of every nation. Multidimensional interpretation of a social reality is created, complementing interdisciplinarity of scientific research.

The use of multivariate approach enriches the study with synchronization of the above components bringing into focus economic entity's activities, interests, resource capabilities and potential. All that enables to identify more accurately the correlations of the entity's features, affecting their behavior in the economic sphere, impact of potential aspects, and of 
moral potential in particular, interconnections of objective-subjective aspects of reality as well as historical and territorial distinctness.

Integrative pattern, that is a network of internal and external human existence, which is a living system, represents transdisciplinary approach combining different areas of theoretical knowledge with regard to their specificity recognition and their autonomy preservation. This approach makes it possible, through science, to emphasize the existence of the unity of the world common principles, reality levels, complex systems, to integrate and synthesize knowledge, to ensure the convergence of meanings at a higher metatheoretical level of abstraction. The key principle is mutual interference, enrichment and interaction of various scientific disciplines. It transforms methods of modern scientific research that links scientific knowledge and solves real social problems. The fact that phenomenon of moral potential in the field of socio-economic activity should be studied in terms of overlapping competences in a number of sciences is the reason for the study to be conducted within the framework of this very approach.

\section{Result}

S.V. Mareeva [1], I. Erev and A.E. Roth [2], Zh.T. Toshchenko [3] and many others, working in the field of a national economic science and in economic sociology in particular, draw attention to the fact that it is social behavior of an individual, driven by their needs, that influences the economy. They claim about the existence of typical behavioral patterns of both individual and collective type, that are based on existing in the society economic activity models, thus emphasizing the cognitive nature of typical behavior and interaction. They also point out correlation of useful properties, value of the goods and use of resources in order to satisfy human's needs, as well as desynchronization of experiences and decisions based on benefits and rational goals.

This tendency can be noticed in the works of foreign scientists such as Tom Burns и E. Roszkowska [4], D.A. Savzh [5] and others who pay particular attention to the study of typical models of personal behavior and the principles of their violation. The scientists note the difference in behavior of people who follow their experience and those who abandon it for the sake of important benefits and goals and because of extreme or changing conditions. Such foreign researchers of economic cooperation as P. Teixeira [6], Y. Benkler [7], G.V. Kolodko [8] emphasize importance of tradition, mentality, values and objective historical conditions and their interdependence. R..J Cebula, J.S. Hall, F.G. Mixon, J.E. Payne [9] point to impact of the environment on opportunities for growth and restrictions on the activities of entities in economic sphere. A. Rustichini, C.G. De Young, J. Anderson, S.V. Burks [10] focus on the influence of personal traits and cognitive abilities of an individual on economic activity performance and future economic results.

Unfortunately, the study of an individual's economic behavior patterns often does not focus on deep intrinsic level of human development, following the movement up the life ladder, but rather on ad hoc changes and temporary periods of human life caused by migration, natural disasters, risky situations, which surely affect essential underlying development basics and unconscious behavior mental matrices, but do not transform them. These irrational aspects of behavior are only partially touched upon in the works of N.V. Grishin et al [11].

The system of goal-setting and achievements is determined by the deep values of the people, which determine behavior in the economic sphere. As noted in her studies, D.B. Kazantsev [12], even during the crisis periods of the late XX, early XXI centuries. among 693 subjects aged $15-29$, where $63.9 \%$ of women and $36.1 \%$ of men, the most significant 
were social values $(93.4 \%)$, then vital $(92.5 \%)$, after moral $(82.3 \%)$, religious $(41.2 \%)$, political (31.0\%), aesthetic (16.3\%) (Fig. 1).

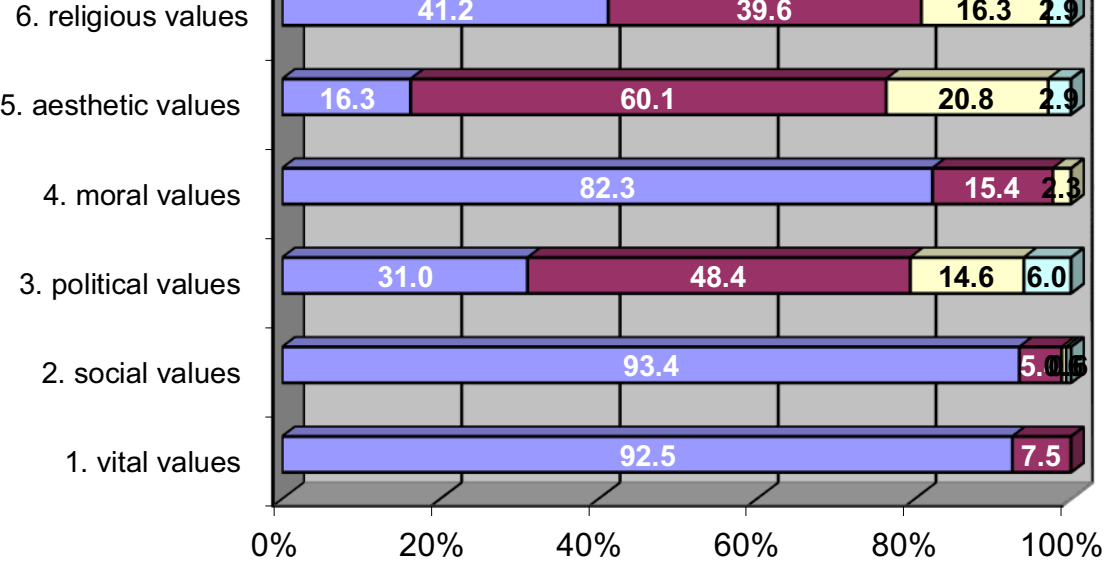

⒈ 1. very significant

口2. significant, but not very much

ロ3. practically insignificantuch

口4. it does not matter

Fig. 1. The importance of value groups.

At the same time, the character traits characteristic of Russians remained, such as responsiveness (56.9\% highly developed, $40.3 \%$ sufficiently developed), kindness, love for people (44\% highly developed, $50.4 \%$ sufficiently developed), compassion (40.1\% highly developed, $54.7 \%$ sufficiently developed), honesty (38.0\% highly developed, $55.7 \%$ sufficiently developed), mercy (29.9\% highly developed, $61.1 \%$ sufficiently developed), sacrifice (5.2\% highly developed, 55.6\% sufficiently developed), etc. (Fig. 2).

It is from the point of view of the value-semantic nature of Russians, their target attitudes that, according to S.D. Bodrunov [13], a mechanism for regulating production, focusing on such indicators as culture, nature, rationality, as opposed to economic rationality and unlimited interference in human nature. Reasonableness criteria are replacing criteria based on monetary gain (Table 1).

At the same time, in the modern world, the needs for knowledge, for trust, for public recognition, for self-realization become prevailing over the needs for the absorption of life's benefits and the amount of absorbed benefits. Knowledge-intensive production is a necessary next stage of development, integrating with culture, namely, with the upbringing of the individual, the upbringing of a person (Table 2). 


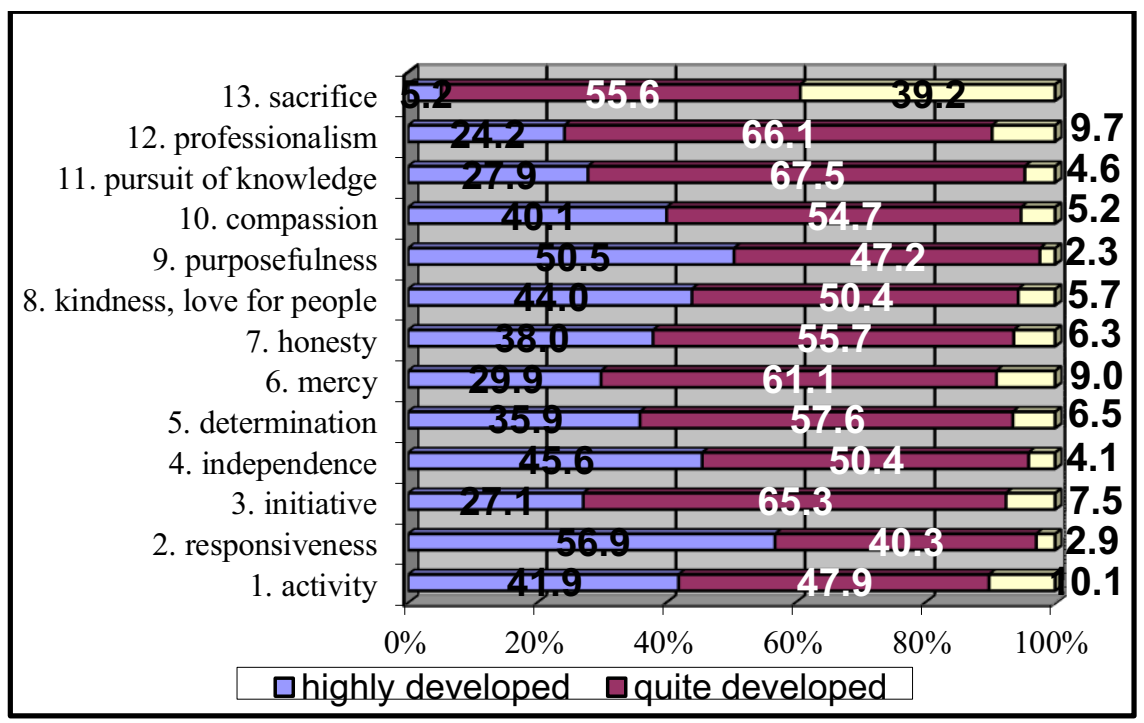

Fig. 2. Manifestation in your character of the following qualities.

Table 1. Different types of rationality.

\begin{tabular}{|l|l|}
\hline \multicolumn{1}{|c|}{ Economic rationality } & \multicolumn{1}{c|}{ Noorationality } \\
\hline $\begin{array}{l}\text { Production objectives - economic: } \\
\text { increase in production and consumption in } \\
\text { monetary terms }\end{array}$ & $\begin{array}{c}\text { Production purpose: satisfaction } \\
\text { of specific reasonable needs }\end{array}$ \\
\hline Increased consumption of resources & \multicolumn{1}{c|}{$\begin{array}{c}\text { Self-limiting consumption only to } \\
\text { reasonable needs based on cultural criteria }\end{array}$} \\
\hline Increasing the resource load on & \multicolumn{1}{c|}{$\begin{array}{c}\text { Unlimited growth of the } \\
\text { technosphere }\end{array}$} \\
\hline $\begin{array}{l}\text { Rationalization of relations with nature } \\
\text { Control over the rationality of technological } \\
\text { application of knowledge }\end{array}$ \\
\hline $\begin{array}{l}\text { Unlimited intervention in human nature in } \\
\text { pursuit of economic efficiency of } \\
\text { production and consumption }\end{array}$ & $\begin{array}{l}\text { Reasonable criteria } \\
\text { intervention in human nature }\end{array}$ \\
\hline
\end{tabular}

Table 2. Development of knowledge of intensive production.

\begin{tabular}{|l|l|}
\hline \multicolumn{3}{|c|}{ Knowledge intensive production } \\
\hline $\begin{array}{l}\text { Development and dissemination of } \\
\text { knowledge aimed at expanding } \\
\text { technological capabilities }\end{array}$ & $\begin{array}{l}\text { Development } \\
\text { dissemination of knowledge aimed at } \\
\text { assimilating cultural values }\end{array}$ \\
\hline \multicolumn{3}{|c|}{ Formation of no-intensive production (no-production) } \\
\hline
\end{tabular}

Failure to take into account the above leads, according to the author, to the development of a catastrophic scenario for the development of both an individual country and all civilizations (Table 3 ).

In this case, economic sphere of life of a particular nation and cause-and -effect relationship of emerging distortions should be considered in terms of mentality and mental development programs, people's traditional matrices, their essential potential issues and especially moral ones. Economic consciousness and behavior, response options and social connections are formed by an individual's environment at the macro-, meso- and microlevels. The reasons for economic behavior are hidden in mental programs and mental matrices of behavior that mediate self-realization of an individual's potential in the sphere of 
economic activity. In Russia, for example, determinative basis is an individual's moral potential.

Table 3. Factors of the crisis scenario of the development of civilization.

\begin{tabular}{|c|}
\hline Immensely growing and predominantly simulative needs \\
\hline $\begin{array}{c}\text { the possibility of losing control over development in pursuit of the satisfaction of } \\
\text { artificially inflated needs }\end{array}$ \\
the level of technological development is already extremely high and allows \\
irreparable damage to civilization \\
the dependence of a person on the technical and information environment is \\
increasing \\
the accelerating growth of man-made "technetic species" to the detriment of the \\
rapidly displaced diversity of biota species \\
growing technological load on the environment \\
advancing development of the technosphere while lagging behind in the development \\
of that part of the social human consciousness that is "responsible" for the rational use of \\
technological advances \\
weakness of internal regulators of reasonable behavior, determined by the content \\
and level of development of culture
\end{tabular}

The works by A.V. Lubskiy [14] contain a crucial idea that it is Russian people value systems, their beliefs and attitudes significantly affect all fields of social development, including the sphere of economy. On the basis of philosophical and theoretical analysis of the studies, conducted by Russian and foreign scientists, considering behavior trends, the author proved that personal and economic behavior is caused by synchronization of material interests, resource capacity and value regulatory potential.

From the point of view of D.B. Kazantseva [15], it is moral potential that by maintaining generic, mental basics as a source of strength, motives and inner activity of an individual acts as the major foundation of personal intrinsic development of an individual as well as all spheres of society. The phenomenon of "moral potential of a person" embodies multidimensional nature of human existence, movement of underlying essential vital forces coming into existence through a certain mental program, which acts as a generic archetypal foundation for formation and self-realization (the generic archetype of a person's moral qualities and an algorithm for moving up the steps of spiritual development), providing both the way for subjective identification with ontological content of spiritual basics and specificity of an individual development trajectory of a moral personality, revealing their moral and intrinsic character.

Economic behavior is a reaction driven by moral potential manifestating in the economic sphere and expressed through a set of actions in the process of exchange and consumption. The reasons for economic behavior are determined by the presence or lack of potential. That is what makes a person's attitude to situations and optimization of economic results.

\section{Discussion}

Economic sphere is based on household traditions of economic mentality of the people, which determine the nature of their behavior. Mentality possesses a national identity and is permeated with the spirit of national culture, its values and notions; it is unique for each nation. Mental unconscious matrices provide stable and unchanging patterns of personal and social behavior. Being applied to the sphere of economic activity, it is mentality that creates its forms and mechanisms, influencing the specifics of economic behavior. Economic behavior meets the needs of an individual and society through its unique attitude to material 
goods and their reproduction, realization of potential as well as to a special movement up the life ladder. In different versions, this problem was touched upon by foreign and domestic scientists, namely E.I. Titova [16], A.N. Sorochaikin, I.A. Sorochaikin [17] and many others.

The analysis of works by A.V. Lubskiy [18] showed that the author provided theoretical analysis of research in this area and explained specifics of normative and modal patterns of mental programs of economic behavior in Russia formed under the influence of the matrix and a mobilizing-modernizing social type of state-oriented society development, proving that it is the normative model, as the basis of sociocultural memory of society and economic behavior, that is unconscious and is not very sensitive to external and internal pressure. As a stable foundation for traditional economic behavior, it allows a better understanding of the specifics of contemporary economic behavior of the Russians. At the same time, the mental matrix, which has two modalities - property and labor, is a primary foundation that generates and reproduces economic behavior and its options.

A new relationship impetus launched in the 90s. XX century contributed to creation of a binary nature of Russian economic mentality. Its basic formation factors, namely the content of unconscious, normative traditional economic beliefs, values and attitudes, came into conflict with the intended modal economic concepts, values and attitudes formed under the influence of liberal market reforms.

Mental program of the Russians is dominated by spiritual values correlating with the life goals; therefore, economic activity for some Russians is the life purpose and a way of selfrealization, whereas economic benefit is of secondary importance. The objective of economic activity is beyond the activity itself, which promotes creativity in realizing potential and situation when an individual constructs their life at a spiritual level. Therefore, modern economy that does not aim at the actualization of potential itself, does not contribute to the development of human potentials in the spiritual and material spheres.

Considering satisfaction of the lower level human needs as the goal of production and economic order is largely due to the contradictions inherent in the works of a philosopher, economist, sociologist Karl Marx, where the purpose is substituted by means. The goal appears not to satisfy the increasing needs approaching selfrealization and determining development, but to satisfy the inferior physiological needs. Defining labor as "the first vital need", the scientist presented labor not as a means to an end, but as the end itself.

This comes in contradiction with the laws of personal development, described by psychological science in numerous studies of labor and self-realization where labor presents a means to the end, rather than the goal. So, for example, in the works of Erich Fromm it is noted that the history of man is the history of their self-realization, carried out precisely through labor and production.

When self-realization of a person's potential is transformed from a goal into a means, and labor turns from a means into the end, a person turns into a production resource, and their potential turns into a potential opportunity that could be realized. There is no movement of a person along the steps of a spiritual development, self-realization stops, potential is not revealed. Economic sphere, like all other areas of life, is deteriorating since the situation contradicts to the laws of human development and blocks the mechanisms of their personality self-actualization. There is no self-expression of potential, which determines unique transformation of the product, means and labor instruments. Interference with moral potential realization blocks its entity, aimed at naturally uniting man and nature, stimulating their uniqueness and launching production of quality outcomes, developing production.

In scientific literature on economic sphere of human activity, they do not associate resource opportunities, attitudes, values and preferences of an individual with self-realization of potential and its moral foundations as well as with the spiritual goals and meanings of 
society development. At the same time, economic prosperity and crisis issues solution is only possible on the basis of essential foundations of the specifics of people's economic mentality, understanding the content of its variability and differences in the mental matrix of economic behavior with its moral potential, which determines behavioral scenarios and reflects typical life situations. The mental matrix of economic mentality determines standard interaction of both rational and irrational character.

However, according to the majority of domestic and foreign scientists, nowadays the XXI global financial and economic crisis continues to destroy Russian world and its mentality by means of the current monetary policy, creating such a system. According to the experts, anticrisis measures taken by the Russian government are being implemented slowly and ineffectively. The bifurcation point, the crisis point has been passed, and there is a wide range of possible ways of solving a number of internal and external contradictions arisen: from revolution and civil war, to the world redivision. The geography of war is expanding and the struggle for influence through technological growth and redistribution of economies is intensifying. Financial elites spread their influence beyond their own countries, becoming supranational systems, creating critical infrastructures, models of the world conquest, asserting their standards through the struggle.

Moreover, back in 1992, Gary Becker was awarded the Nobel Prize for his research on human capital. In modern sociology, the "main modern contradiction" is revealed: it is the contradiction of formation and flow of human capital, which can be explained by a synonym, that is, human potential. This concept and its numerous synonyms are introduced in different studies without describing its intrinsic distinctive features. It is claimed that people and society cannot survive in the world of civilization crisis without fulfilling their potential, unlocking its core. It is noted that none of the existing societies are engaged in human potential development considering it as a resource not to be used in high technology sphere.

In the scientific literature they consider a concept of Homo Economicus as an actual model of Homo Sapiens who acts to obtain the best possible personal welfare [19] and discuss transition from Homo Sovieticus to Homo Economicus through actions performed for the economic reasons that takes place in Russia at the moment. Among numerous versions of a new man the priority is given to a so-called " noo " approach (nooproduction, nooneeds, noodevelopment) [20] which is interpreted as a reasonable focus on actual human values and on intensive technology and production [21]. A concept gaining popularity and becoming a subject of discussion of scientists in all spheres is the one of the noosphere by V.I. Vernadsky[22], namely production of human beings within the framework of production and social relations, satisfying certain cultural and moral criteria that was arranged for them.

Scientists claim that man is primarily a "noo" object, that is, intelligent and focused on human values rather than a "zoo" object that focuses on biological matters [23] and goodssimulators, satisfying needs and requirements created artificially, which changes the scope of basic human needs. Scientists are developing a holistic vision of a contemporary qualitative leap that transforms understanding of man as a biological being into the one with social, cultural and moral needs. The imperatives are being selected that are meant to be general moral guidelines, providing the basis for socialization, humanization and civilization of economic relations and institutions. Researchers are trying to unite two sides of a single process: rational and irrational, material and moral.

Generalization of modern research shows that society goes through the stages of development, reaching the spiritual stage. Each stage is distinguished by its specificity of development and functioning of the psychic mechanisms of the individual, by the stage-bystage satisfaction of needs. The consumer society, on the contrary, is moving from higher stages of development to lower ones. The result is the satisfaction of needs located only at 
the lower levels, namely physiological ones. It is not the development and self-realization of man that takes place, but his degradation. In this regard, scientists are looking for a key problem that causes such a restructuring.

In fact, a summary of modern research shows that consumerist society is moving along "the stages of their moral life being" [22] not in the direction of their growth, achieved by step-by-step transition of an individual from the stage of vital life activities, socio-dynamic and socio-cultural activities onto a the stage of cultural and moral development with appropriate progressing and functioning of psychic mechanisms of the personality at each stage and gradual satisfaction of superior needs; on the contrary, they are moving from superior stages of development to the inferior ones. As a result only the needs located at the lower rungs of the ladder, namely physiological ones, are satisfied and it is not a development and self-actualization that takes place, but a degradation. In this regard, scientists are looking for a key problem that causes such a restructuring.

A global event is created by local events. This implies both struggle and dialectic. Relationship between a part and a whole has an entity basis. The necessity to refer to a whole is caused by cause-and-effect relationship and implementation algorithm. As long as there is no ontological vision, there is no integrity of the country, no holistic attitude to the subject, no correlation between constituent parts of a single system. Without a holistic treatment of the tissue of a single organism, functioning of its individual parts will not be restored.

Philosophical and universal ontology explains any event that occurs in reality in terms of the laws of its development. It is on the choice of "imperatives" intended for controlling the development of the entire production range, from material to moral matters as well as and the of a human, building certain production and social relations in order to manage production, that depends the development and the future of a single country and all mankind. This position is becoming not only relevant, but also fundamental.

Russia is a country that has historically been at the ontological level, has abandoned it in recent years, displaying this through moral, essential, potential loss in people and society. In history of Russia, there were the times of compliance with the human potential actualization; there were also times of loss of compliance with the requirements of an ontological system. Those disasters lessons show the reasons for catastrophes happened, that was the lack of ontological and consequently general technological control.

Philosophical analysis provides the following ontological criteria for what is happening. Russia as a country is a system, an integral organism that has unified moral imperatives of management. Development of the subject, being the country's foundation and determining its evolution as that of a single system, can meet the universal and natural laws or it cannot. If the content of the subject ceases to comply with the ontology, then the implementation of the entity, moral and potential goals does not take place that disposes fall of technological process, destruction of businesses and all the systems.

"Homo Economicus" is a person that has lost the entity, potential and ontological certainty. An alternative to them is a person who fulfils their spiritual and moral potential, thanks to which a high-tech production could be built. In this regard, economic development of a country and other spheres of activity should begin precisely with the correction of a personality in accordance with the ontological context, their synchronization, and unlocking their potential. Manifestation of potential matters and their realization in economic processes unites existence and human's life into a single coherent whole, exhibits ontological in the processes of human existence, through interrelation and unification.

As a matter of fact, technological development needs require a global self-identification of a person with their entity, moral, and potential aspects. This is necessary to regulate crisis, minimize global catastrophes, and relieve tension. Since everything in the world is based on self-identification, that determines the direction of development and the points of defense, 
self-identification of economy with moral potential protects both the process itself and this potential's operation. This self-identification creates a holistic vision of objective reality and encourages realization of potential, as a manifestation of the entity in the sphere of economy.

The object of self-identification of the majority of Russian population mentality comprises intrinsic underlying moral entity that influences the mechanisms of development in all spheres, including economy. New modern technological opportunities should not transform traditional component or oppose to it, disrupting continuity in realization of the potential stored in traditional aspects of culture. The only possible action is effective transforming of moral potential fulfillment for creating a comfortable environment within the framework of rapidly changing conditions, taking into account the intensity of the processes.

Modern world requires a deeper study and consideration of irrational and rational aspects in behavior of an individual under the effect of social transformations. The process of exchange and consumption implies investment of human potential, thus satisfying their development needs. Human potential is the basis of existence, with inexhaustible energy and strong dynamics. The economy, connecting an individual with their potential, mental models, and hence the needs, resources, values and the society where they fulfill their potential, is intended to create a moral and material integrity, where people manifest themselves developing and implementing their potential, intrinsic and moral aspects of their development in specific material forms. Manifestation of human potential and exactly moral potential in the processes of exchange and consumption is an important basis for the development of economy.

\section{Conclusions}

The economy created by people for the good of people and ensuring the process of their consumption is determined by people themselves and their potential. Economic behavior is a reaction, depending on personal preferences and value-normative potential, to resourceful opportunities of creating, producing and disposing of material goods. In this regard, the only aim this process can have is realization of personal potentials, and namely moral potential being a characteristic of the Russian mentality and feeding its body, as a manifestation of intrinsic, free, individual, organically holistic and united with ontological, natural, noospheric component. Manifestation of uniqueness inherent in the potential by the very nature develops science, creates new technologies, and innovatively transforms reality, pushing the state to new frontiers of development.

It is precisely moral potential in the sphere of social and economic activity, by concretizing ontology and preserving the essence, unlocks human potential, resolves contradictions and minimizes disasters. Moral imperatives of the potential due to the cultural and spiritual stages of social development, serving as growth points, are the only way out of civilizational crisis and transition from consumerist society to a potentially developing one.

Essential foundation manifested in mentality creates stability of individual and group preferences, determining their reactions to changes. Meeting the needs of potential development through the sphere of economic activity provides a person with an upward development along the life ladder, with a special balancing at each stage of external and internal resources. Considering a person primarily as a moral and then a material system with biological processes, that is capable of adapting to changing conditions, making decisions quickly and responding to crisis situations, is the only modern vector of economic development.

Economic sphere is determined by the state institutions that shape the economic behavior and economic thinking of the subjects of relations. At the same time, basing of state 
institutions on national history, moral meanings, traditions and mentality of people, determined by moral potential and moral norms of behavior, is vital.

\section{References}

1. S.V. Mareeva, Inequality of life chances of Russians in the sphere of life and labor balance, Monitoring of public opinion: economic and social changes 3 (151), 324-344 (2019) DOI: 10.14515/monitoring.2019.3.18

2. I. Erev, A.E. Roth, Maximization, learning, end economic behavior, Proc. Natl. Acad. Sci. USA 111, 3, 10818-10825 (2014) DOI: 10.1073/pnas.1402846111

3. Zh.T. Toshchenko, Precarnaya employment - a phenomenon of modern economics, Sociological research 8, 3-13 (2020) DOI: 10.31857/S013216250009904-7

4. T. Burns, E. Roszkowska, Rational Choice Theory: Toward a Psychological, Social, and Material Contextualization of Human Choice Behavior, Theoretical Economics Letters 6, 2, 195-207 (2016) DOI: 10.4236/tel.2016.62022

5. D.A. Savage, Surviving the storm: Behavioural economics in the conflict environment, Peace Econ. Sci. Public Policy 105-129 (2016) DOI: https://doi.org/10.1515/peps-20150047

6. P. Teixeira, Gary Becker's early work on human capital: Collaborations and distinctiveness, IZA Journal of Labor Economics. Springer. Heidelberg 3, 1-20 (2014) http://dx.doi.org/10.1186/s40172-014-0012-2

7. Y. Benkler, The wealth of networks : how social production transforms markets and freedom (Yale University Press. New Haven and London, 2006)

8. V.M. Geets, A.A. Gritsenko, Grzegoz V. Kolodko, Economic theory, Kiev: Institute of Economics and Forecasting of the National Academy of Sciences of Ukraine 16, 1, 519 (2019) DOI: 10.15407/etet2019.01.005

9. R.J. Cebula, J.C. Hall, F.G. Mixon, J.E. Payne, Economic behavior, economic freedom and entrepreneurship, Economic Behavior, Economic freedom and Entrepreneurship 131 (2015) DOI: 10.4337/9781784718237

10. A. Rustichini, C.G. De Young, J. Anderson, S.V. Burks, Toward the Integration of Personality Theory and Decision Theory in Explaining Economic Behavior: An Experimental Investigation, Journal of Behavioral and Experimental Economics 122137 (2016) DOI: 10.1016/j.socec.2016.04.019

11. N.V. Grishina, "Self-change» of personality: possible and necessary, Bulletin of St. Petersburg State University. Psychology and Pedagogy 8, 2, 2, 126-138 (2018) DOI : 10.21638/11701/spbu16.2018.202

12. D.B. Kazantseva, Transformational Processes of the Spiritual Potential of a Personality (Monograph. Penza: PSU Publishing House, 2010)

13. S.D. Bodrunov, Noonomics (Monograph. M.: Cultural revolution, 2018)

14. A.V. Lubsky, R.A. Lubsky, V.P. Voitenko, Individualism and Modal Models of Social Behavior in Russian Society, Humanities in the South of Russia 6, 3, 225-239 (2017) DOI: $10.23683 / 2227-8656.2017 .3 .20$

15. D.B. Kazantseva, Self-realization of the spiritual and moral potential of the individual in Russia (Monograph. Prague: Vědecko vydavatelské centrum "Sociosféra-CZ", 2020)

16. E.I. Titova, The essence and originality of the manifestation of the economic mentality of the Russian person, Manuscript. Tambov: Gramota 12, 9, 130-133 (2019) DOI : $\underline{10.30853 / \text { manuscript.2019.9.27 }}$ 
17. A.N. Sorochaikin, I.A. Sorochaikin, A look at homo economicus and its economic behavior through the prism of ontological assumptions, Fundamentals of Economics. Management and Law 5 (24), 28-31 (2020) DOI: 10.51608/1727190589

18. A.V. Lubsky, et al., Mental programs and models of social behavior in the Russian society (Monograph. Rostov-on-Don: Science and Education Foundation, 2016)

19. P. Weise, Homo economicus and homo sociologicus: the horrors of the social sciences, Journal of Sociology 18, 2, 148-161 (1989) DOI: https://doi.org/10.1515/zfsoz-19890205

20. S.D. Bodrunov, To the question of a comparative analysis of the theories of noonomy and socialism, Questions of political economy 3, 52-66 (2020) DOI: 10.5281/zenodo.4067045

21. S.D. Bodrunov, Global Risks in the space of a pandemic: the practice confirms the theory noonomiki, Economic Reviving ix Russia 2 (64), 4-14 (2020) DOI: $10.37930 / 1990-9780-2020-2-64-4-14$

22. A.A Yashin, Development of V.I. Vernadsky about the transition of the biosphere to the noosphere, Bulletin of new medical technologies. Tula: Tula State University 23, 2, 189196 (2016) DOI: 10.12737/20447

23. S.D. Bodrunov, From ZOO to LEO: man, society and production in the conditions of a new technological revolution, Problems of Philosophy 7, 109-118 (2018) DOI : $\underline{10.31857 / \mathrm{S} 004287440000232-0}$ 